\title{
Sustainable Competitive Advantage: Case Studies of Dell, Ikea and Byte Dance
}

\author{
Ding Ding ${ }^{1, \dagger}$, Xinyue $\mathrm{Liu}^{2, \dagger}$, Haoran $\mathrm{Xu}^{3, *, \dagger}$ \\ ${ }^{1}$ North China Electric Power University, China \\ ${ }^{2}$ School of Business, University of Wollongong, NSW 2522 Australia, \\ ${ }^{3}$ Alliance Business School, University of Manchester, Manchester, UK \\ ${ }^{*}$ Corresponding author. Email: haoran.xu-2@postgrad.manchester.ac.uk \\ These authors contributed equally.
}

\begin{abstract}
Sustainable competitive advantage is the foundation to ensure the survival and development of enterprises amid the fierce market competition. For a long time, how to obtain and maintain sustainable competitive advantage has been the core issue in the field of strategic management. Based on the resource-based theory and the continuum model proposed by Tannebaum in 1958, this study puts forward a theoretical model on how to maintain the sustainable competitive advantage of enterprises under the factors of market transformations. In line with this model, the cases of Dell, IKEA and Byte Dance have been respectively reviewed to investigate how they perform under three market transformation scenarios of technological change, ecological deterioration and social crisis. The results of this analysis confirm the significance of sustainable competitive advantage in today's business world.
\end{abstract}

Keywords: Sustainable competitive advantage, Market transformation, Dell, Ikea, Byte Dance.

\section{INTRODUCTION}

Sustainable competitive advantage refers to a unique business strategy to maintain priority within a certain time frame [1]. This priority position, comprising three levels concerning the economy, environment and society, is difficult for competitors to imitate [2].

General Electric CEO Jack Welch once said: "If you don't have a competitive advantage, then don't compete." For a long time, gaining and maintaining a sustainable competitive advantage has always been a focal point for strategic management. Different schools of strategic management have different understandings of competitive advantages, including but not limited to Andrews et al.'s SWOT model [3], Michael Porter's Five Forces Model, B. Wernerfelt and J. B. Barney's resourcebased theory [4], etc. However, since they are all based on the steady-state environment in which the enterprise is located, they cannot explain the nature and source of the sustainable competitive advantage of the enterprise in a turbulent environment.

In the history of business, many outstanding companies have achieved great success, such as Kodak, Nokia, etc.. Still, they have finally declined because they failed to adapt to the rapid changes of the times. In essence, they lack the continuous innovation ability to adapt to different stages of the life cycle. When the static equilibrium of the steady-state market is constantly broken, their competitive advantage cannot persist. This has led some schools to claim that sustainable competitive advantage is obsolete and no longer works. They advocate transient competitive advantage because some industries are changing too quickly to create sustained performance.

However, experience completely contradicts the theory of transient advantage. According to the resourcebased theory, short-term advantages (such as costs) can be easily competed or imitated, while long-term advantages come from resources and capabilities. When sudden technological changes, ecological deterioration and social crises break the balance of the original market, the incremental effect of path dependence will be gradually eroded, and short-term competitive advantages will dissipate under the erosion of market competition. Under such circumstances, only by adopting innovative technologies or new business models can companies maintain their strong long-term competitive advantages and obtain excess profits that exceed the industry average. 
In other words, in the rapidly changing external environment, companies not only hope to gain a competitive advantage at a certain point in time, but also hope to resist the erosion of competitors in the long term and maintain their existing competitive advantages. The view of a sustainable competitive advantage to produce a steady stream of profits has never been outdated.

\section{CONTINUUM OF SUSTAINABLE COMPETITIVE ADVANTAGE}

In a turbulent environment, companies cannot simply rely on certain competitive advantages to survive for a long time. To "live forever", they need to constantly develop new competitive advantages as an alternative to existing competitive advantages that are declining in performance. That is to say, enterprises should develop another new competitive advantage before the previous competitive advantage begins to decline. Thus, enterprises build an interconnected or successive "continuum" of competitive advantages $[5,6]$.

In this article, market transformations are taken as a variable to construct a continuum of sustainable competitive advantage as a theoretical model. In the turbulent market environment, the innovation of enterprises is a continuous process without intermission, thus forming a cycle (Figure 1). Through the continuous transformation of competitive advantage, enterprises can smoothly transition from the present to the future, form a continuous forward path, and obtain a sustainable competitive advantage.

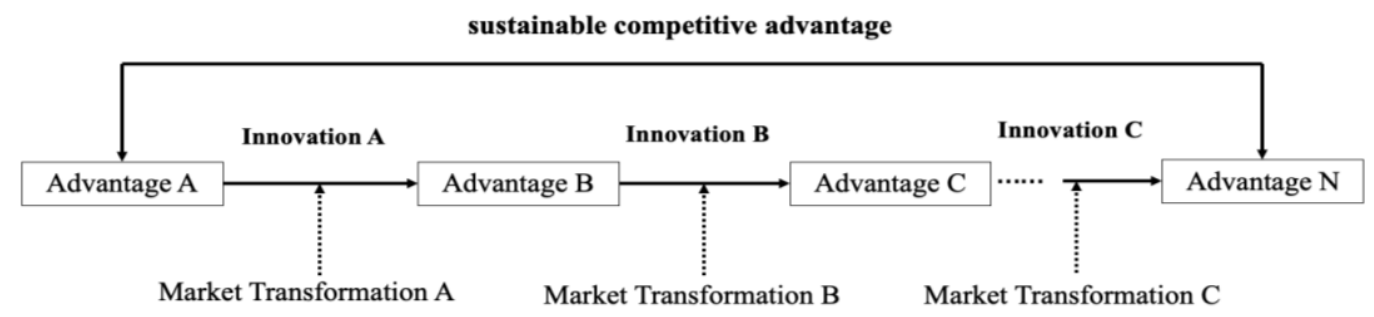

Figure 1. Sustainable competitive advantage model

\section{CASE STUDY OF DELL}

Next, this article studies the cases of Dell, Ikea, and Byte Dance under the three major market transformation scenarios of technological changes, ecological deterioration and social crisis. It supports research on the necessity of maintaining sustainable corporate economic, environmental and social competitive advantages.

First, with the strengthening of the global integration trend and the acceleration of technological innovation, the original market structure and industry competition rules are quickly broken, making the competitive environment in which companies are more complex and uncertain. This requires companies to quickly respond to changing customer needs and adapt to the market through continuous technological iterations, thereby relying on sustainable competitive advantages to obtain stable profits.

Dell has experienced three stages of development, from a traditional enterprise to an Internet and ecommerce enterprise, and now to a technology group is the most successful example.

Dell was originally established as a company that sold computers by telephone. Although many achievements have been made, when the Internet revolution began, Dell did not hesitate to move all of its business online and made full use of the Internet to provide users with personalized customization and delivery services. In this way, customer satisfaction has been greatly improved.
Dell has miraculously maintained a growth rate of more than $50 \%$ for many years, becoming one of the world's largest computer manufacturers and posing a huge threat and challenge to other competitors that have been slow to transform.

This advantage lasted until 2006. With the continuous innovation of emerging e-commerce and the reduction of profits of standardized hardware products under IT service, not only was HP and Acer surpassed in the PC industry in 2006 and 2009, but also the profits of enterprises began to decline for the first time in 2007 [7]. Dell's competitive advantage at that time had been brought into full play, and it could no longer become Dell's sustainable advantage. During this period, Dell quickly adjusted its strategy. While breaking the single direct selling mode, it plans to follow the forefront of science and technology to carry out digital transformation, and create network service business and enterprise solution business through self-development and acquisition, including storage, data center, security, virtualization, network, software, etc. Until 2016, after integrating EMC (the world's largest enterprise storage manufacturer), Dell changed its name to "Dell Technology Group". Its business covers the fields of edge computing, data center and cloud, and completely transformed from a marketing company to a technologybased company. From Figure 2, it can be seen that Dell's strategy of digital transformation at that time was successful, and the company's revenue and profit bottomed out and rebounded ten years later. 


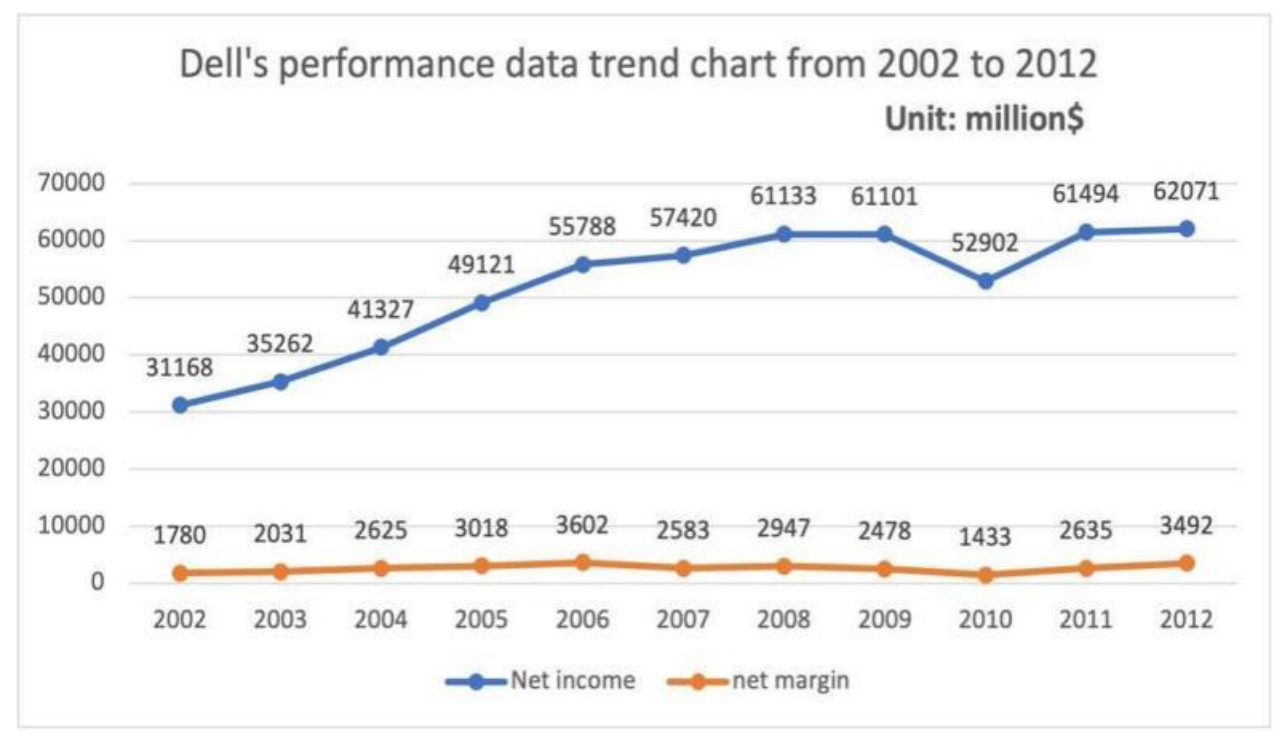

Figure 2. Financial performance of Dell (2002-2012)

In 2019, with the outbreak of the Covid-19 virus, the global economy has been severely damaged. At the moment of crisis, Dell kept up with the times to innovate again, open up medical and life sciences businesses, carry out a digital transformation of healthcare, and provide interconnected medical technologies and Dell EMC solutions for global hospitals. Up to now, $65 \%$ of American hospitals have used Dell EMC storage infrastructure [8]. Through innovative business transformation, Dell has successfully turned the global epidemic environment into a profitable business background.

In the era of the digital economy, the new generation of information technology represented by the Internet continues to innovate and accelerates penetration and integration with the manufacturing field. Thus, the company's strategic goals and development motivation must undergo profound changes. Assuming that when the Internet age comes and Dell remains the same, insisting on direct sales by telephone, Dell will lose its steady cash flow and never become the king of direct selling companies with a sustained dominant position today. Assuming that Dell fails to adjust its strategic deployment and create a perfect innovation ecosystem in time when the data in 2006 declines, Dell will gradually lose its sustainable advantage like its old rival HP. Today, Dell's business has become richer in breadth and depth. It has not only innovated the healthcare business but also laid out future-oriented technologies such as cloud computing, the Internet of things, artificial intelligence and AR/VR. Dell's three-stage innovation perfectly fits the sustainable competitive advantage model mentioned above. Therefore, enterprises should aim at the world's most cutting-edge technologies and technologies following the requirements of productivity development, regardless of economic costs and short-term economic benefits, to create a sustainable competitive advantage.
Second, since the 21 st century, as the global climatic problem becomes more severe, the international community's response to global climate change requires the development of a low-carbon economy and the transition to a low-carbon society. A view based on natural resources asserts that the environment will limit the ability of enterprises to sustain competitive advantages [9]. In response to environmental issues, companies should adjust their industrial structure and resource utilization models to deal with the risks and opportunities of global climate change and further infiltrate sustainable development ideas into contemporary corporate decisions and culture to transform potential threats into competitive advantages [10].

\section{CASE STUDY OF IKEA}

Eiadat (2008) believes that through the development of new green technologies, energy conservation and other innovative behaviors, companies can reduce costs or provide differentiated products to gain a competitive advantage over their competitors [11]. For instance, IKEA is a Swedish furniture company founded in 1943. As the company continues to expand rapidly and steadily, its product range has spread to cover a variety of furniture items. IKEA becomes the largest furniture retailer globally, which distributes in 43 countries, opens 180 chain stores, and employs more than 70,000 employees [12]. Some critics suspect that IKEA, a company that relies on a business model that is low-cost, high-volume and mass-produced, can ever be sustainable. According to news reports in recent years, IKEA does perfectly turn the Eiadat (2008) theory of green innovation into practice. IKEA is committed to offering consumers more sustainable options and inspiring people to positively impact the planet through sustainable consumption. In Ikea's philosophy, it dictates that the less waste created, 
the cheaper the product. At present, $60 \%$ of IKEA's products are made of renewable materials, and $10 \%$ of its products contain recyclable materials [13]. The low cost of raw materials means that products made from renewable resources are relatively cheap. Consequently, IKEA's green products are made at low prices while maintaining high-quality standards. In this way, IKEA keeps competition out by being a low-cost provider. Moreover, consistently low pricing can help build brand loyalty and make the business of IKEA more competitive.

The company keeps working towards becoming climate positive by 2030 through increasing usage of sustainable materials, plant-based foods and renewable energy sources [13]. This sustainable mission leads to building a powerful brand regarding the sustainable competitive advantage. IKEA will get a great company reputation by being environmentally friendly and it will cause customers to prefer the brand over competitors.

By making a product differentiation that focuses on quality, green technology, and customer service, Ikea also builds a sustainable competitive advantage. For example, ISTAD plastic bags are designed with resealable seals for easy reuse. These bags are usually made of sugar cane materials, which are renewable [14]. Due to their durability, resealability, and ability to be reused repeatedly, they are a simple choice for the reduction of trash bag waste. Not only does IKEA use eco-friendly materials, but their product designs are simple, fresh, and natural. As a result, these advantages contribute to better product differentiation, which in turn builds customer loyalty and makes the company less likely to lose market share to its competitors.

Green innovation is the key to solving sustainability issues and enhancing the organization's competitive advantage. Companies with green innovation capabilities can win consumers' favor by providing new green products, improving environmental standards, and establishing industry entry barriers, thereby maintaining a sustainable competitive advantage in long-term market competition.

However, the lockdowns caused by COVID-19 severely affected IKEA throughout 2020 in many different ways. According to IKEA's Financial Report (2020), $75 \%$ of stores worldwide were closed for an average of seven weeks in 2020, and the retailer's sales were 39.6 billion in 2020, which is lower than the 41.3 billion it was in 2019. The number of IKEA store visits decreased from 1 billion in 2019 to 825 million in 2020 [15].

In response to COVID-19, core marketing concepts are continuously evolving and transforming the marketing environment, forcing IKEA to increase its entrepreneurial skills and hypermobility by adapting to changes and developing new marketing strategies [16]. A boom in the use of online communication and social media has forced firms to switch both their sales and marketing efforts online. Even though the IKEA physical stores reopened, the online sales still remained high, which demonstrates a change in consumer purchasing behavior caused by the pandemic and lockdowns where people preferred the constant access to browse IKEA products online [15]. IKEA has faced many challenges in 2020 , but it still managed to innovate by enhancing its supply chain and investing in its social media. IKEA has hired and trained employees to manage customer communication online [15]. Besides, to provide customers with the inspiring, simple and smart shopping way, the Ingka Group has rolled out the IKEA app to about 12 countries which are available for customers to order through for home delivery and store pick-up [17]. With the trend of shopping via the app, customers are also increasingly turning to remote planning of their homes. One of the co-workers in the store will be in a special "remote planning suite" while the customer stays in the comfort of their own home and is connected via phone [17]. The perfect kitchen or desired space will then be created remotely. Besides, several countries, such as Austria, have offered contactless click \& collect services [17]. The handover of goods ordered online takes place outside the IKEA store on a "drive-in basis", and is $100 \%$ contactless. By taking these innovative business transformations, IKEA has actively and efficiently responded to the global epidemic issues which fit the market transformation 3 in the model above.

Third, as the Covid-19 spreads rapidly to every corner of the world, the global economy and the supply chain have been hit by unprecedented shocks. Except for certain industries (industries related to online services, such as Amazon) that have benefited from the current crisis, most industries are facing the challenge of losing sustainable competitive advantages, and some SMEs are even facing the risk of bankruptcy. Governments of many countries in the world are actively adopting loose monetary policies to simplify borrowing and have implemented many economic stimulus measures, including tax breaks, but for business leaders, these measures may not be effective immediately. In this case, it is particularly important to rely on sustainable competitive advantage to obtain steady cash flow to survive the crisis.

\section{CASE STUDY OF BYTE DANCE}

During the period of major market transformation like the epidemic, many Chinese companies made flexible adjustments and innovations to their business methods to maintain a sustainable competitive advantage. For example, the free model has become a high-frequency vocabulary in people's daily life. Byte Dance bought the network broadcasting rights of the movie "Lost in Russia" and played it on its streaming platform TikTok and Watermelon Video for free. Online English 
Enlightenment App Jiliguala provided free resources to children across the country. In fact, from the standpoint of the enterprise, the introduction of the free model is a way of propaganda to maintain its sustainable competitiveness. The free model is based on consumers' willingness to use and "word-of-mouth effect". As a marketing strategy in a specific period, it can help companies expand user groups in the short term and effectively tap potential customers. But it is worth noting that this model is not free from start to finish. With the increase of user stickiness and the expansion of the market scale, the later charges gradually offset the former costs, so that the company has obtained long-term and stable cash flow, and realized a curve overtaking in the business strategy.

The profit model of Douyin, owned by Byte Dance, is based on expanding the user base and number to achieve profitability. In short, it attracts users by stimulating the public's desire to express and create, rapidly increase the number of users and their usage of the software, improve the stickiness of the users, and ultimately achieve profitability. In the end, content is the key differentiator, which makes the app so successful. Most importantly, it can handle kinds of regulatory regimes and censorship policies across various nations to create a safe, healthy online space [18].

And after the arrival of the epidemic, which brought a series of operational difficulties to many corporations, Douyin had more opportunities in this situation by trying to find a new competitive advantage and also taking its social responsibility at the same time. Because of the restrictions imposed by the epidemic, offline shopping has also been restricted, and Douyin has vigorously developed its advantages in online shopping. Unlike other e-commerce platforms, Douyin, which has a certain fan base, has created a more personalized and youthful live atmosphere with its own unique advantages. Douyin's strong ability to bring goods life cannot be underestimated. Generally, in the combination of "live + link", the bottom of the short video with links to goods, click directly into the e-commerce platform to place orders. Take the "Double Eleven" during the epidemic in 2020 as an example, the cumulative turnover of the platform was 17.6 billion.

Also, Byte Dance provides rich "recharge" content for users who stay at home during the epidemic, bringing gyms, cinemas, museums, theaters, etc. to the cloud, providing a path for everyone to become a more fulfilled and better version of themselves. More than 11 million users have participated in Douyin's “online gym"; more than 900 celebrities and arts volunteers have been teaching art through the platform. Based on their strengths, each platform under Byte Dance provides comprehensive support for various industries to resume work, school and business online, helping people to resume their lives, work and study as soon as possible, and assisting small and medium-sized enterprises and farmers who have suffered a huge impact to find new opportunities.

Consequently, when the external environment falls into a social crisis, enterprises should start from their industry and actual operating conditions and spare no effort to seek ways to maintain sustainable competitive advantages. Enterprises can improve the core competitiveness of their products and services by making flexible adjustments and innovations to commercial methods and avoid intensifying corporate losses due to blind competition and excessive costs.

\section{CONCLUSION}

From the above three cases, it can be concluded that Dell through technological innovation, IKEA through reducing green production costs, and Byte Dance through flexible adjustment of business models, have all obtained sustainable competitive advantages.

Therefore, in this study, it can be inferred that sustainable competitive advantage of enterprises is crucial to all industries. It can be further argued that the sustainable gradually accumulated in long-term business practice and has a close relationship with a period of business philosophy, industry dynamics, and market situation.

In conclusion, companies need to adapt to market changes in the ever-changing external environment and carry out self-innovation to maintain their own sustainable competitive advantage. Because sustainable competitive advantage is the foundation of a company's survival, providing an inexhaustible impetus for the company's foothold can ensure long-term development in a fierce market environment. Enterprises must identify and adapt to environmental changes, give full play to their advantages in resources and capabilities, and seize fleeting market opportunities in order to achieve corporate strategic leapfrogging.

\section{REFERENCES}

[1] Barney, J. (1991). Firm resources and sustained competitive advantage. Journal of management, 17(1), 99-120.

[2] Ahmad, A. (2015). Business intelligence for sustainable competitive advantage. In Sustaining competitive advantage via business intelligence, knowledge management, and system dynamics. Emerald Group Publishing Limited.

[3] Ansoff, H. I., \& Andrews, K. (1965). The concept of corporate strategy.

[4] Wernerfelt, B. (1984). A resource-based view of the firm. Strategic management journal, 5(2), 171-180. 
[5] Tannenbaum, R. (1958). How to choose a leadership pattern. Harv. Bus. Rev., 36, 95-101.

[6] Xuewei Jiang. (2002). Sustained competitive advantage of enterprises in a turbulent environment. Management Frontline. 2, 18-24.

[7] DELL (2021). 2012 Annual report: DELL.

[8] DELL (2021). Dell technologies. Available at: https://www.delltechnologies.com/zh$\mathrm{cn} /$ industry/healthcare-it/index.htm? $\sim \mathrm{ck}=\mathrm{mn}$ (Accessed: 7th July 12, 2021).

[9] Hart, S. L. (1995). A natural-resource-based view of the firm. Academy of management review, 20(4), 986-1014.

[10] Li, Y., Ye, F., Sheu, C., \& Yang, Q. (2018). Linking green market orientation and performance: Antecedents and processes. Journal of Cleaner Production, 192, 924-931.

[11] Eiadat, Y., Kelly, A., Roche, F., \& Eyadat, H. (2008). Green and competitive? An empirical test of the mediating role of environmental innovation strategy. Journal of World Business, 43(2), 131-145.

[12] IKEA Foundation (2021). Available at: https://ikeafoundation.org/about/ (Accessed: 7th July 12, 2021) .

[13] IKEA (2021). More sustainable, every day. Available at: https://www.ikea.com/gb/en/this-isikea/sustainable-everyday/ (Accessed: 7th July 12, 2021).
[14] IKEA (2021). IKEA This is IKEA - ISTAD. Available at: https://www.ikea.com/us/en/this-isikea/sustainable-everyday/istad-a-pioneeringgoody-bag-pubb724aa6a (Accessed: 7th July 12, 2021).

[15] IKEA Financial Report (2020). Inter IKEA Group Financial Summary FY20. Available at: https://gblsc9u2-prd-cdn.azureedge.net/-

/media/interikea/igi/financial-reports/inter-ikeagroup-financial-summary-fy20-

03112020.pdf?rev=3a909f2cdead4ecfbf2c1dd026e 954f5\&hash=0A92D3F6A6820

A818192608A67F28DD3 (Accessed: 7th July 12, 2021).

[16] He, H., \& Harris, L. (2020). The impact of Covid19 pandemic on corporate social responsibility and marketing philosophy. Journal of Business Research, 116, 176-182.

[17] Ingka Group (2021). IKEA Retail: leveraging technology in Coronavirus times I Ingka Group. Available at: https://www.ingka.com/news/ikearetail-leveraging-technology-in-coronavirus-times/ (Accessed: 7th July 12, 2021).

[18] Ma, Y., \& Hu, Y. (2021). Business Model Innovation and Experimentation in Transforming Economies: ByteDance and TikTok. Management and Organization Review, 17(2), 382-388. doi:10.1017/mor.2020.69 